\title{
Integration of standardization and customization: impact on service quality, customer satisfaction, and loyalty
}

\begin{abstract}
The basic objective of this study is to analyse the direct and indirect impacts of standardization and customization on customer satisfaction and loyalty through service quality. The service quality has two dimensions: technical quality and functional quality. A framework is developed by extending GrLn nnroosômodel of service quality by including the antecedents of service quality. A questionnaire-based survey collected data from 315 customers of three service industries: healthcare, hospitality, and education. The data was analysed and the model validated using PLS-SEM. The findings show that: (1) integration of standardization and customization of service offerings is critical for improved service quality; (2) standardization has higher impact on service quality when compared to customization; (3) functional quality has higher impact on customer satisfaction when compared to technical quality; and (4) customer satisfaction has a significant effect on customer loyalty. The contribution of this study is the development of an integrated framework to analyse the roles of standardization and customization on service quality.
\end{abstract}

Keyword: Standardization; Customization; Service quality; Customer satisfaction; Customer loyalty; Malaysia 